\title{
Affixation in Ardalani Kurdish Based on Distributed Morphology
}

\author{
Foroogh Kazemi \\ Department of Linguistics, Central Tehran Branch, Islamic Azad University, Tehran, Iran \\ Rozita Ranjbar \\ Central Tehran Branch, Islamic Azad University, Tehran, Iran
}

\begin{abstract}
-among the recent generative grammar approaches to explain morphology, the distributed morphology approach can be mentioned. In this approach there is no place as lexicon or morphology for formation of words and word formation is occurred after syntax processes. The present research is trying to introduce distributed morphology as a non-lexicalist approach and consider the phenomenon of affixation in Ardalani Kurdish language by this approach. The research results indicate that affixation and the process of forming plural nouns can be explained by distributed morphology approach.
\end{abstract}

Index Terms - distributed morphology, affixation, late insertion, syntactic level, morphological level, Ardalani Kurdish

\section{INTRODUCTION}

The distributed morphology approach was mentioned for the first time by Halle and Marantz (1993). This theory is not specific to morphology but takes the task of word production from lexicon and distributes it among grammatical parts to provide the same analyze of morphologic and syntactic structures (Haugen, 2008, p. 21). In distributed morphology, morphology and syntax have interaction and direct relationship with each other so that syntactic characteristics are occurred in morphology directly (Embic, 1997, p. 28). In contrast to former generative theories, the morphemes that take part in word formation are affected by syntax and real words don't enter in sentence until syntax ends, which means that the sentence structure forms before the presence of the word and the words that are more adapted to the obtained syntax structure are selected from mental lexicon. In this theory, syntax specifies the part of speech of each element and also is able to make word and sentence. Thus no element belongs to the pre- syntactic grammatical part of speech. In this approach also affixes are morpheme. But in contrast to former approaches, terminal elements of syntax are distinguished from phoneme occurrence. In the other words it can be said that in distributed morphology, affixes also are morpheme but their phoneme occurrence is after syntax.

Kurdish language is of the category of north western Persian languages that is a branch of Indian and Iranian languages belonging to Indo-European language family (Ebrahimi and Daneshpazhouh, 2008). Sanandaji or Ardalani dialect belongs to central Kurdish dialect (Sorani) group. This research intends to test the performance of distributed morphology approach in Kurdish language. The problem in present study is that if distributed morphology approach has the ability to describe and explain the affixation process in Ardalani Kurdish language. And how the process of forming plural nouns in Ardalani Kurdish as a sample of affixation in this approach is done. Therefore, for conducting the research, the data of this dialect have been collected on the field. And the research was conducted according to distributed morphology approach in descriptive-analytical method. Heretofore, some studies about Kurdish language and Ardalani dialect have been done from different aspects. However, the dialect has not been studied and examined from the aspect of distributed morphology. The present study should be considered due to it has innovative goals and provides background for other studies in this field.

\section{REVIEW OF THE RELEVANT STUDIES}

A large number of linguists have considered distributed morphology study in different sections; for example, "Aspect and Tense Projections in the Agentive Adjectives based on the distributed morphology theory" Anooshe (2015), "PostSyntactic Word Formation in Persian" Sasani and Aftabi (2012), "Statistical Approach to Distributed Morphology" Modarres Khiyabani (2012) can be mentioned. Also Shaghaghi (2012) in "Post-Syntactic Morphology" study describes distributed morphology approach and defines basic concepts in the approach. Ghatreh (2012) in her study as" Inflection in Distributed Morphology" considers verb inflection in Persian from the distributed morphology aspect". In his/her opinion, morphologic characteristics of verb stem are in terminal nodes and are achieved through various syntactic mechanisms such as core movement, in distributed morphology. These syntactic mechanisms add morphologic morpheme to verb in the form of affix. Rafiei (2012) in "distributed morphology and affixation" study introduces distributed morphology theoretical foundations and examines the phenomenon of affixation briefly. Among Non- 
Iranian linguists who had researches in the field of distributed morphology, Halle (1997), Marantz (1988), and Halle and Marantz (1994) can be mentioned.

Smriti and Vaijayanthi (2010) studied nominal inflection in Hindi within the framework of distributed morphology according to Halle \& Marantz (1994) and Harley and Noyer (1999). Müller (2002, 2003, 2004) for German, Icelandic and Russian nouns respectively and Weisser (2006) for Croatian nouns used distributed morphology approach to study nominal inflectional morphology. They investigated the inflectional categories, inflectional classes, morphological processes operating at syntax, the distribution of vocabulary items and readjustment rules for Hindi nouns (Smriti and Vaijayanthi, 2010, p. 308). The earlier researches about Hindi inflectional morphology were only descriptive studies of nominal and verbal categories and their inflections without discussing the role or status of affixes that take part in inflection. In these studies, the discussion of the mechanisms (morphological operations and rules) used to analyze or generate word forms are ignored. Moreover, these researches do not consider syntax-morphology or morphologyphonology mismatch during the course of word formation. They studied a large number of Hindi Noun forms which were collected from news items but evaluated them manually to verify the results. The result indicated that many of the words were left unidentified due to incorrect and variant spelling. Also, a large number of compound nouns with hyphens remain unidentified. Many entries were also uninflected nouns. Because the lexicon lacked entries.

Müller (2005) studied the core system of noun inflection in Icelandic based on distributed morphology. According to his idea, a conspicuous property of Icelandic noun inflection is that a small set of inflection markers is used to generate a large number of inflection classes (Müller, 2005, p. 230). Constant re-use of inflection markers implies that there is syncretism in abundance (Müller, 2005, p. 230). He believes that, such syncretism comes in two varieties. First, there are two cases that share a single marker; he refers to this (standard) kind of syncretism that holds within a given inflection class as intra-paradigmatic syncretism. Second, there may be two or more inflection classes which share one single marker (Müller, 2005, p. 230). He argues that a substantial number of these instances of syncretism can be derived systematically. This makes it necessary to refer to natural classes of cases and inflection classes, respectively (Müller, 2005, p. 230). Such natural classes result from decomposing standard case features (like [nom], [acc]) and inflection class features (like [class 1], [class 2]) into more primitive features: Cross-classification of these features yields full specifications representing cases and inflection classes (Müller, 2005, p. 230). Underspecification regarding these features gives rise to natural classes of cases and inflection classes that inflection markers can then refer to. Besides, the set of inflection markers which he proposes for Icelandic noun inflection will be shown to meet an iconicity requirement, to the effect that the form of an inflection marker and its function correlate (Müller, 2005, p. 230). He believes that the special choice of morphological theory becomes relevant: Whereas feature decomposition and underspecification are devices that can be used in many other morphological theories (Müller, 2005, p. 230). Distributed Morphology is unique in assuming the operations of impoverishment (see Noyer, 1992).

Harley and Noyer (1999) describe the structure of distributed morphology. Based on their explanation, there are three core properties which distinguish distributed morphology from other morphological theories: late insertion, underspecification, and syntactic hierarchical structure all the way down (Harley and Noyer, 1999, p. 3). They believe that unlike the theory of LGB (Chomsky 1981) and its lexicalist descendants, in distributed morphology the syntax proper does not manipulate anything resembling lexical items, but rather, generates structures by combining morphosyntactic features (via Move and Merge) selected from the inventory available, subject to the principles and parameters governing such combination (Harley and Noyer, 1999, p. 3). According to their believes, late insertion refers to the hypothesis that the phonological expression of syntactic terminals is in all cases provided in the mapping to phonological form (Harley and Noyer, 1999, p. 3). That means, syntactic categories are purely abstract, having no phonological content. Only after syntax are phonological expressions, called vocabulary items, inserted in a process called Spell-Out. This is more valuable that this hypothesis is stronger than the simple assertion that terminals have no phonological content (Harley and Noyer, 1999, p. 3). They believe that, there is essentially no pre-syntactic differentiation between two terminal nodes which have identical feature content but they will eventually be spelled out with distinct vocabulary items such as dog and cat (Harley and Noyer, 1999, p. 3). Harleyand Noyer express that underspecification of Vocabulary Items means that phonological expressions need not be fully specified for the syntactic positions where they can be inserted. Hence there is no need for the phonological pieces of a word to supply the morphosyntactic features of that word; but, vocabulary items are in many instances default signals, inserted where no more specific form is available (Harley and Noyer, 1999, p. 3). They believe that, syntactic hierarchical structure all the way down entails that elements within syntax and within morphology enter into the same types of constituent structures (such as can be diagrammed through binary branching trees). Distributed morphology is piece-based in the sense that the elements of both syntax and of morphology are understood as discrete constituents instead of as morphophonological processes (Harley and Noyer, 1999, p. 3).

\section{DistriButed MORPHOLOGY}

Distributed morphology is not a theory particular to morphology. And because of not having a lexicon, the tasks related to lexicon is done through grammar and other areas. Three functional characteristics of distributed morphology that distinguish it from lexicalist minimalism are late insertion, morphosyntactic decomposition, and underspecification that were mentioned by Halle and Marantz (1994, p. 275). Terminal nodes in late insertion process, which are seen as 
hierarchical structures after syntactic derivation, have syntactic and semantic characteristics; but not phoneme ones. Phoneme content appropriate to each derivation after spell-out is inserted in its corresponding terminal node (Ambic and Noyer, 2001:558). Since insertion of lexical elements will be occurred after syntax, it is called late insertion (Marantz, 1997, p. 205). The second characteristic of distributed morphology is morphosyntactic decomposition that based on that roots and functional nodes will be merged in syntax and the third is underspecification. In distributed morphology the insertion of lexical units in terminal nodes relies on the assumption of underspecification of morphosyntactic characteristics. Based on that assumption, there is no need to characteristics of lexical units to be exactly given to insert a syntactic node (Ambic and Noyer 2007). In fact, underspecification is required that syntactic characteristics be determined before selection of lexical element that realizes these characteristics (Bobaljik, 2001, p. 13).

In this approach, the lexicon will be omitted completely and with different contents of different elements will be replaced that contrast to the lexicon, none of them are computational. First content contains units required by syntax including roots and a set of grammatical characteristics, which are determined by universal grammar and some principles of each language. This content is named limited lexicon (Marantz, 1997, p. 203). Second content contains the dictionaries that are created for terminal nodes and have Phonemic manifestation in syntax. And third content is encyclopedia. In the encyclopedia, special meanings of roots with regard to their syntactic contexture are listed. All of the complex units are created by applying head movement and merge mechanisms. Merge in addition to syntax can also apply changes in post syntax in offered structures. Merge can change structural relationship between two elements.

$$
\beta+\alpha \longrightarrow \alpha+\beta
$$

In first stage of merge a root namely lexical morpheme merges with a functional morpheme. The root lacks grammatical information and its part of speech is determined after being merged with the functional morpheme. In next stage, the whole structure can be merged with another functional morpheme. This process may be repeated several times. The following graph shows how lexical and grammatical morphemes merge with each other.

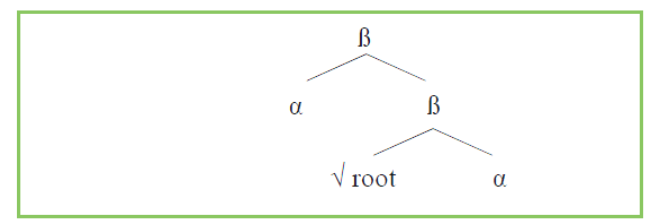

In addition to syntactic merge and movement processes, there are some post syntactic processes that occur in phonetic section and change the obtained structure to some extent. In distributed morphology the morphology expression is used to indicate the word formation processes that occur not in syntax but in phonetic section.

\section{A. Affixation in Distributed Morphology}

There is no direct indication to affix in distributed morphology neither as morphologic nor derivational. Therefore, in this approach there is no distinction challenge between derivation and morphology and the only difference between derivation and morphology elements is the ability of functional morphemes to determine some grammatical aspects of lexical morphemes. For example, it can determine its part of speech. In distributed morphology the final word formation is result of operation of syntactic merge and movement processes and also morphological process in phonetic form. In the approach, initial elements of syntax namely morphemes lack phonetic content and their phonetic content is offered in phonetic form. The mechanism offering phonetic form to morphemes is known as word insertion mechanism. According to the above descriptions, we examine the affixation process of plural noun suffix in Ardalani Kurdish using distributed morphology approach in the following.

\section{B. The Lexicalist Hypothesis and Distributed Morphology}

Harley and Noyer (1999, p. 3) believe that, there is no lexicon in distributed morphology in the sense familiar from generative grammar of the 1970s and 1980s (Harley and Noyer, 1999, p. 3). That means, distributed morphology unequivocally rejects the Lexicalist Hypothesis. The jobs assigned to the Lexicon component in earlier theories are distributed through various other components. For linguists committed to the Lexicalist Hypothesis, this aspect of distributed morphology may be the most difficult to accept, but it still is a central tenet of the theory. The fullest exposition of the anti-Lexicalist stance in distributed morphology is found in Marantz (1997a). There, Marantz discuses against the generative lexicon, adopted in such representative examples of the Lexicalist Hypothesis as Selkirk (1982) or DiSciullo and Williams (1987), using arguments from the very paper which is usually taken to be the source of the Lexicalist Hypothesis, Chomsky's (1970) 'Remarks on Nominalization'. Marantz (1997a) believes that it is crucial for Chomsky's argument that, for example, a process like causativization of an inchoative root is syntactic, not lexical (Harley and Noyer, 1999, p. 3). Chomsky argues that roots like grow or amuse should be inserted in a causative syntax, in order to derive their causative forms. If their causative forms were lexically derived, nothing should prevent the realization of the causativized stem in a nominal syntax, which the poorness of *John's growth of tomatoes indicates is 
impossible (Harley and Noyer, 1999, p. 3). Other lexicalist assumptions about the nature of lexical representations, Marantz notes, are unproven: no demonstration has been made of correspondence between a phonological "word" and a privileged type of unanalyzable meaning in the semantics or status as a terminal node in the syntax, and counterexamples to any simplistic assertion of such a correspondence are easy to find. Because there is no lexicon in distributed morphology, the term "lexical item" has no significance in the theory, nor can anything be said to "happen in the lexicon", and neither can anything be said to be "lexical" or "lexicalized" (Harley and Noyer, 1999, p. 3). Because of the great many tasks which the lexicon was supposed to perform, the terms "lexical" and "lexicalized" are in fact ambiguous. They note a few of the more usual assumptions about lexicalization, and indicate their status in the distributed morphology model: I Lexical (ized) = Idiomatized. Because the lexicon was supposed to be a storehouse for sound-meaning correspondences, if an expression is conventionally said to be "lexicalized" the intended meaning may be that the expression is listed with a specialized meaning in distributed morphology such an expression is an idiom and requires an encyclopedia entry (Harley and Noyer, 1999, p. 3). Based on their believes, the internal structure of expressions is clearly not always a product of syntactic operations (Harley and Noyer, 1999, p. 4).

\section{DATA ANALYSIS}

In Ardalani Kurdish there are four plural noun suffixes / -ât/, /-hâ /, /-ân/ and /-gāl/ that adhere to the end of word (noun) and create plural words. Among these affixes, /-ân/ and /-gǣl/ affixes have more application and are used in general in this language, while / -ât/ and /-hâ / have not general application and are limited.

TABLE I.

PLURAL MAKER SUFFIXES IN ARDALANI KURDISH

\begin{tabular}{|l|l|l|l|}
\hline Row & Plural maker suffixes & Plural words & Meanings \\
\hline 1 & -ân & Mâlân & Houses \\
\hline 2 & -gæl & mnałgæl & Children \\
\hline 3 & -hâ & Čethâ & Things \\
\hline 4 & -ât & xæyætât & dreams \\
\hline
\end{tabular}

As was mentioned before, based on Marantz point of view the word insertion process in distributed morphology offers phonetic characteristics to plural morpheme. And relationship between word and morpheme is assumed bilinear. Since common phonetic signs in Ardalani Kurdish language are / -ât/, /-hâ /, /-ân/, and /-gǣl/, based on mentioned viewpoint, phonetic signs of these suffixes are offered to plural morpheme.
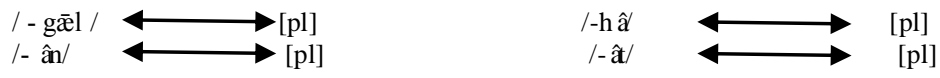

Among determined words to be inserted in terminal node, it is likely that more than one word, two or more, have the insertion conditions. Since in the end, only one word should be inserted in a special position, the words are placed in a competitive situation. The selection of one word among competitor words is done under supervision of subset principle. The principle was mentioned by Halle (1997) that based on that the phonetic form of a word is inserted in a position if that word is coincident with all or a subset of determined characteristics for that position. If word has characteristics in which there isn't morpheme, insertion process will not be occurred. When several words have the insertion conditions, the word that has the most coincident characteristics will be inserted. In Ardalani Kurdish language among four plural morphological suffixes, the /-ân/ and /-gǣl/ suffixes have the connection ability to different nominal basis, animate or inanimate; in other words, have more application in this language. As a result, the suffixes have more chance in competition with other plural noun suffixes.

In the following tables, how plural noun suffixes are admitted by animate or inanimate nouns in Ardalani Kurdish is shown.

TABLE II.

THE PROCESS OF AFFIXATION IN THE WORD “HOUSE” IN ARDALANI KURDISH

\begin{tabular}{|l|l|l|}
\hline Row & Plural maker suffixes & Meanings \\
\hline 1 & -ân & mâłân \\
\hline 2 & -gæl & mâłgæl \\
\hline 3 & -hâ & *mâłhâ \\
\hline 4 & -ât & "mâłât \\
\hline
\end{tabular}

TABLE III.

THE PROCESS OF AFFIXATION IN THE WORD "WOMAN" IN ARDALANI KURDISH

\begin{tabular}{|l|l|l|}
\hline Row & Plural maker suffixes & Meanings \\
\hline 1 & -ân & žnân \\
\hline 2 & - gæl & Žngæl \\
\hline 3 & -hâ & "̌̌nhâ \\
\hline 4 & -ât & žnât \\
\hline
\end{tabular}


According to the merge process, the lexical morphemes (root) only beside the functional morphemes have part of speech. As mentioned before, these morphemes lack phonetic content and their phonetic manifestations are determined in word insertion stage. For example, in words such as houses =/mâłgǣl $/$, women =/žngæl/, children =/mnâlân $/$, and boys =/kořân/ the words /mât/, /žn/, /mnât/ and / koř/ are considered as roots and the suffixes /-gǣel/ and /-ân / are considered as grammatical morphemes that during the merge process operate as follow. When the word is singular, the phonetic form of plural noun suffix is null in word insertion process. The following graphs show above mentioned words formation.

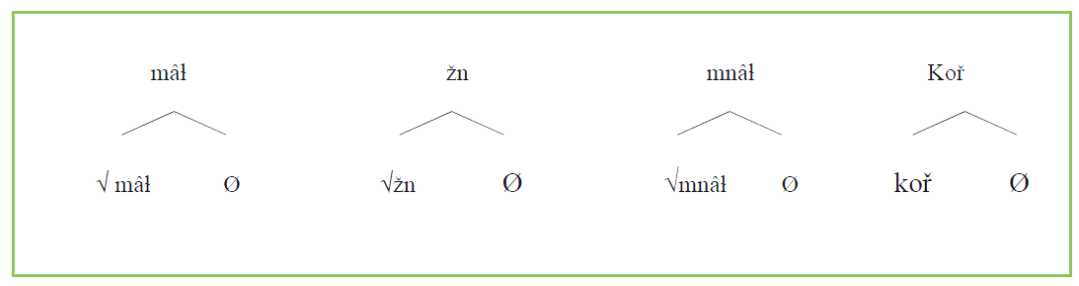

In next stage a derivation process occurs for forming plural word. In this stage, phonetic manifestation of grammatical morpheme is not null. The following graphs show how the affixation process of plural noun suffix occurs in Ardalani Kurdish based on the distributed morphology.

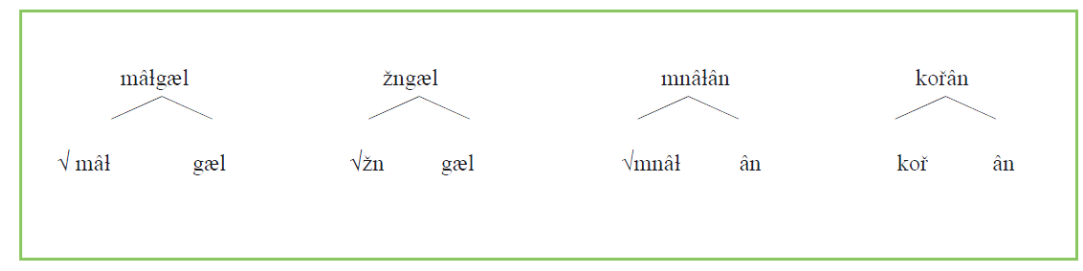

Therefore, according to above graphs, it can be concluded that the affixation process is explainable in distributed morphology approach in Ardalani Kurdish. Since in distributed morphology there is no subject as distinction between derivational and morphological affix, thereupon all of the affixes (lexical and functional) make new words through the merge process. In the affixation process after competition of morphemes with each other, in the end the morpheme that has more coincident characteristics with root is selected and participates in the derivation process with root and manifests phonetically in terminal nodes in vocabulary insertion stage.

\section{CONCLUSION}

Examining the affixation process of plural noun suffix in Ardalani Kurdish based on the distributed morphology approach, it can be concluded that the approach has the ability to describe and explain the affixation process in Ardalani Kurdish. Since distributed morphology includes two merge and movement fundamental processes, lexical and grammatical affixes participate in the merge process. During the competition of morphemes to join to root, the affix that has more coincident characteristics enters to vocabulary insertion stage and in the end manifests phonetically in the terminal node. In distributed morphology there is no distinction between derivational and morphological affix and morphemes include two lexical (root) and functional (grammatical) categories. Thus, root's affixes select coincident morphemes and merge with them. In Ardalani Kurdish, for example, the morphemes for forming plural noun were studied according to distributed morphology approach and how they merge with root was shown in graph. Thereupon the affixation process in this language is explainable by distributed morphology approach.

\section{REFERENCES}

[1] Anooshe, Mazdak. (2015). "Aspect and Tense Projections in the Agentive Adjectives based on the Distributed Morphology Theory", Language Researches: Nom. 26, pp. 49-72. [In Persian].

[2] Bobaljik, J. D. (2001). The Ins and Outs of Contextual Allomorphy. Ms. McGill University: Montreal.

[3] Chomsky, N. (1970). Remarks on Nominalization. Readings in Transformational Grammar, edited by R. A. Jacobs \& P. S. Rosenbaum, 184-221. Waltham, Mass.: Ginn.

[4] Chomsky, N. (1981). Lectures on Government and Binding. Dordrecht: Foris.

[5] DiSciullo, A. \& E. Williams. (1987). on the definition of word. Cambridge, Mass.: MIT Press.

[6] Ebrahimi, M., Daneshpazhouh, Z. and F. (2008), "Clitics and their Semantic - Syntactic Relations to Verbs in Kurdish language (Surani Dialect)". The Research Journal of Human Sciences: No. 58, pp.145-168. Shahid Beheshti University. [In Persian].

[7] Embick, D. (1997). "Voice Systems and the Syntax/Morphology Interface.” In The Proceedings of the Penn/MIT Workshop on Aspect, Argument Inquriy. Vol. 32. Nom. 4., pp. 555-595. 
[8] Embick, D. and Noyer, R. (2007). "Distributed Morpholgy and the Syntax-Morphology Interface" In The Oxford Handbook of Linguistic Interfaces, ed. G. Ramchand and C. Reis, Oxford University Press, pp. 289-324.

[9] Ghatreh, Fariba. (2012). "Inflection in Distributed Morphology", the first morphology seminar researches, Tehran: Nevise publication, pp. 37-57. [In Persian].

[10] Halle, M. (1993). "Distributed morphology and the Pieces of Inflection", in K. Hale \& S.J. Keyser (Eds). The View from Building 20, Cambridge (Mass), MIT Press, pp. 111-176.

[11] Halle, M. and Marants, A. (1994). "Some key features of distributed Morphology". In: A. Carnie \& H. Harley (Eds). Papers on Phonology and Morphology MIT Working Papers in Linguistics. Nom. 21. pp. 275-288.

[12] Halle, M. (1997). "Distributed morphology: Impoverishment and fission». In: B. Bruening, Y. Kang \& M. McGinnis (Eds). PF: Papers at the Interface MIT.

[13] Harley, H. and Noyer, R. (1999). "State-of-the-Article: Distributed Morphology", GLOT International, 4 (4), pp. 3-9.

[14] Haugen, J. D. (2008). Morphology at the Interface. Amsterdam: John Benjamins Publishing

[15] Marantz, A. (1988). "Clitics, morphological merger, and the mapping to phonological structure". In: M. Hammond \& M. Noonan (Eds). Theoretical Morphology. pp. 253-270. NY: Academic Press.

[16] Marantz, A. (1988). "Clitics, morphological merger, and the mapping to phonological structure. In M. Hammond and M. Noonan (Eds), Theoretical Morphology: Approaches in Modern Linguistics, 253-270 San Diego: Academic Press.

[17] Marantz, A. (1997). "No Escape from Syntax: Don't Try Morphological Analysis in the Privacy of Your Own Lexicon." University of Pennsylvania Working Papers in Linguistic (Philadelphia, Pennsylvania: Upenn Department of Linguistics), pp. 201-225.

[18] Marantz, A. (1997a). "No escape from syntax: Don't try morphological analysis in the privacy of your own Lexicon". Penn Working Papers in Linguistics, 4:2: Proceedings of the 21st Annual Penn Linguistics Colloquium, (Edited by A. Dimitriadis, L. Siegel, C. Surek-Clark, \& A).

[19] Modarresi Khiyabani, Shahram. (2012). "Statistical Approach to Post Syntactic Morphology”, the first morphology seminar researches, Tehran: Nevise publication, pp. 111-131. [In Persian].

[20] Müller, G. (2002). "Remarks on Nominal Inflection in German". In: I. Kaufmann \& B. Stiebels, eds., More than Words: A Festschrift for Dieter Wunderlich. Akademie Verlag, Berlin, pp. 113-145.

[21] Müller, G. (2003). Syncretism and Iconicity in Icelandic Noun Declensions: A Distributed Morphology Approach. Ms., IDS Mannheim.

[22] Müller, G. (2004). “A Distributed Morphology Approach to Syncretism in Russian Noun Inflection”. Proceedings of Formal Approaches to Slavic Linguistics 12, pp. 353-373.

[23] Müller, G. (2005). "Syncretism and iconicity in Icelandic noun declensions: a Distributed Morphology approach", Yearbook of Morphology, pp. 229-271.

[24] Noyer, R. (1992). Features, Positions, and Affixes in Autonomous Morphological Structure. PhD thesis. Cambridge, Mass.: MIT.

[25] Rafiei, A. (2012). "Distributed morphology and Affixation", the first morphology seminar researches, Tehran: Nevise publication, pp. 59-74. [In Persian].

[26] Sasani, F. and Aftabi, Z. (2011). "Post Syntactic Word Formation in Persian" the third morphology seminar researches, Tehran: Ahura: linguistic Society of Iran, pp. 107-122. [In Persian].

[27] Selkirk, E. (1982). The syntax of words. Cambridge, MA: MIT Press.

[28] Shaghaghi, V. (2012). "Post Syntactic Morphology", the first morphology seminar researches, Tehran: Nevise publication, pp. 13-35. [In Persian].

[29] Smriti S. and Vaijayanthi, M. S. (2010). "Hindi Noun Inflection and Distributed Morphology", Smriti Singh Indian Institute of Technology Bombay Vaijayanthi M. Sarma Indian Institute of Technology Bombay Proceedings of the 17th International Conference on Head-Driven Phrase Structure Grammar Universite Paris Diderot, Paris 7, France 'Stefan Muller (Editor) ' 2010 CSLI Publications, pp. 307-321.

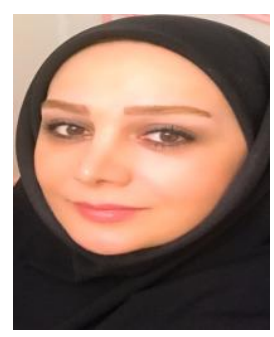

Foroogh Kazemi was born in Iran in 1974. She is head of linguistics department and associate professor of linguistics in Central Tehran Branch, Islamic Azad University in Iran. She has published 53 articles (most of them cited in google scholar) and 15 books in linguistics. She has been teaching at graduate and Ph.D. levels in linguistics. Dr. Kazemi has been advisor, reader and referee of many linguistic theses and judge of articles in journal of linguistics. She is a member of research council in faculty of foreign languages at Central Tehran Branch. She is also a member of editorial board, quarterly of language and literature: Parneyan Kheyal. Her areas of interest are functional linguistics, sociolinguistics, typology and discourse analysis.

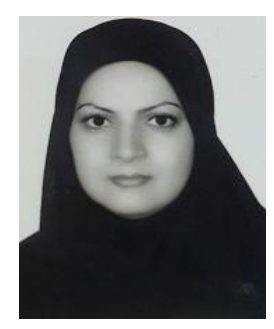

Rosita Ranjbar was born in Sanandaj, Iran. She received an undergraduate degree from the University of Ilam in English literature. She also received her master's degree in linguistics from Allameh Tabatabai University.

She is currently studying at a $\mathrm{PhD}$ in linguistics at Islamic Azad University. She has published an article in the journal of Linguistics and Khorasan Dialects, titled "Case-Marking in Kurdish (Sanandaji and Banei)", Volume 6, No.2, (2014-2015). 